\title{
Bilevel positive airway pressure in two moments after bariatric surgery
}

\author{
(DD) Eli Maria Pazzianotto-Forti ${ }^{1}$ \\ (iD Letícia Baltieri ${ }^{2}$ \\ (iD) Patrícia Brigatto 3 \\ Carolina Moraes da Costa ${ }^{3}$ \\ (D) Maura Rigoldi Simões da Rocha \\ (iD) Irineu Rasera-Júnior ${ }^{4}$
}

\begin{abstract}
1. Programa de Pós-Graduação em Ciências do Movimento Humano, Universidade Metodista de Piracicaba, Unimep, Piracicaba, SP, Brasil 2. Doutorado em Ciências da Cirurgia, Departamento de Cirurgia, Faculdade de Ciências Médicas, Universidade de Campinas, Campinas, SP, Brasil 3. Mestrado em Fisioterapia, Programa de Pós-Graduação em Ciências do Movimento Humano, Universidade Metodista de Piracicaba, Unimep, Piracicaba, SP, Brasil 4. Doutorado em Bases Gerais da Cirurgia, Centro de Gastroenterologia e Cirurgia da Obesidade, Piracicaba, SP, Brasil
\end{abstract}

http://dx.doi.org/10.1590/1806-9282.65.9.1161

\section{SUMMARY}

OBJECTIVE: To investigate the use of Bilevel Positive Airway Pressure (BiPAP) in morbidly obese individuals in two moments following bariatric surgery (Roux-en-Y gastric bypass): post-anesthetic recovery (PAR) and first postoperative day (1PO).

DESIGN: Randomized and blinded clinical trial.

METHODS: We studied 40 morbidly obese individuals aged between 25 and 55 years who underwent pulmonary function test and chest $X$-ray preoperatively, and on the day of discharge (2nd day after surgery). They were randomly allocated into two groups: PAR-G (BiPAP in PAR for one hour), and TPO-G (BIPAP for one hour on the 1PO).

RESULTS: In the PAR-G and 1PO-G, respectively there were significant reductions in slow vital capacity (SVC) ( $p=0.0007$ vS. $p<0.0001)$, inspiratory reserve volume (IRV) ( $p=0.0016$ vs. $p=0.0026)$, and forced vital capacity (FVC) ( $p=0.0013$ vs. $p<0.0001)$ and expiratory reserve volume (ERV) was maintained only for the PAR-G ( $p=0.4446$ vs. $p=0.0191)$. Comparing the groups, the SVC ( $p=0.0027)$ and FVC ( $p=0.0028)$ showed a significant difference between the treatments, while the PAR-G showed smaller declines in these capacities. The prevalence of atelectasis was 10\% for the PAR-G and 30\% for the 1PO-G ( $p=0.0027)$.

CONCLUSION: Thus, the use of BIPAP in PAR can promote restoration of ERV and contribute to the reduction of atelectasis.

KEYWORDS: Pulmonary Atelectasis. Bariatric Surgery. Physical Therapy Modalities. Respiratory Function Tests. Continuous Positive Airway Pressure.

\section{INTRODUCTION}

Recent research by the Brazilian Ministry of Health ${ }^{1}$ shows that $54 \%$ of Brasil's population over the age of 18 is overweight. Among men, $57.3 \%$ are overweight, and among women, $51.2 \%$. Recent estimates by the World Health Organization ${ }^{2}$ show that in 2016, more than 1.9 billion adults (39\%) were overweight and, of these, more than 650 million (13\%) were obese.
Conservative treatment usually consists of diet, exercise, and use of medications; however, that is not effective for weight loss in cases of morbid obesity (body mass index $(\mathrm{BMI}) \geq 40 \mathrm{~kg} / \mathrm{m}^{2}$ ). In these cases, bariatric surgery is considered the most effective therapy for weight reduction with long-term maintenance, positive effects on most cardiovascular risk factors over a 10-year period, excellent effects on es- 
tablished type 2 diabetes, in addition to preventing the development of new cases of this disease ${ }^{3,4}$.

In upper abdominal surgical procedures, mainly by laparotomy, obesity is a risk factor for intra- and postoperative complications when compared to nonobese individuals, due to previous changes in ventilatory function, arising from greater deposition of adipose tissue, especially in the abdominal area ${ }^{5,6}$.

Along with these factors, general anesthesia contributes significantly to changes in respiratory mechanics, increasing the reduction in functional residual capacity (FRC) through the early closure of the small airways and thus reducing lung volumes and capacities ${ }^{7,8}$. Lung alterations during the surgical procedure can persist for days postoperatively, increasing the risk of respiratory complications, duration of hospital stay, morbidity and mortality, and costs to the health system ${ }^{9,10}$.

Several studies have reported the benefits of preand postoperative chest physical therapy for the restoration of lung volumes and capacities and thoracic-abdominal mobility in obese patients ${ }^{11,12}$. The use of positive pressure devices not only contributes to the restoration of pulmonary function, but it is also important for the prevention of atelectasis in the post-operative period ${ }^{13-15}$.

Therefore, the present research group has been studying effective ways to restore lung volumes and capacities and prevent atelectasis in the post-operative period following bariatric surgery. A preliminary study by Baltieri et al. ${ }^{16}$ demonstrated beneficial effects of the application of bilevel positive airway pressure (BiPAP) on the restoration of expiratory reserve volume (ERV) and reduction in atelectasis immediately after extubation, while still in the post-anesthetic recovery (PAR) room. The objective of the present study was to compare the effects of BiPAP application on the immediate postoperative period, while still in the post-anesthetic recovery room, during the first postoperative day, concerning pulmonary function and the prevalence of atelectasis. Confirmation of these benefits can help reduce any restrictions to physiotherapy in the PAR room.

\section{METHODS}

\section{Study design and ethical aspects}

This was a randomized blind study approved by the Research Ethics Committee of the Methodist University of Piracicaba, São Paulo, Brasil (approval 89/12).

\section{Sample Size calculation}

The sample size calculation was based on a pilot study, considering the minimum significant difference $(0,18 \mathrm{~L})$ and standard error $(0,11 \mathrm{~L})$ of the differences between the preoperative and postoperative values for ERV. Using the Mann-Whitney test and adopting a statistical power of $80 \%$ and an alpha of $0.05,20$ volunteers were required per group. The sample size calculation was processed using BioEstat, version 5.3. According to Sood ${ }^{17}$ obesity markedly reduces ERV; therefore, this volume is considered the outcome variable of this study.

\section{Inclusion and exclusion criteria}

People with body mass index (BMI) between 40 and $55 \mathrm{~kg} / \mathrm{m}^{2}$, age between 25 and 55 years, who underwent Roux-en-Y gastric bypass by laparotomy were included. People with abnormal preoperative pulmonary function and chest x-ray, smokers, obstructive sleep apnea syndrome, postoperative hemodynamic instability, with hospital stay greater than three days or postoperative complications were excluded.

\section{Investigators}

The study included three researchers: one responsible for the initial evaluation and inclusion of individuals, one blind to initial data of volunteers and responsible for randomization, and one responsible for treatment application. After the assessment of eligibility, block randomization was carried out using Microsoft Excel $2007^{\circ}$ for allocation into the groups, and a sealed envelope was handed to the investigator responsible for treatment application.

\section{Outcome measures}

Pulmonary function test

For spirometry, a computerized ultrasonic spirometer (Cosmed ${ }^{\circledR}$, PONY, Rome, Italy) was used and calibrated daily. For this procedure, the volunteers were asked to remain seated, with their feet on the floor, wearing a nasal clip.

They were also instructed with appropriate verbal commands to perform the maneuvers of slow vital capacity (SVC) and forced vital capacity (FVC), according to the guidelines of the American Thoracic Society (ATS) and European Respiratory Society $(\mathrm{ERS})^{18}$. Each maneuver was repeated until three acceptable, and two reproducible curves were obtained, not exceeding more than eight attempts. The 
extracted values of each curve were selected according to the recommendations of Pereira ${ }^{19}$. The evaluations were performed in the preoperative period, i.e., before the surgery, and on the day of discharge, i.e., on the second postoperative day.

Before starting the postoperative assessment, the pain was evaluated using the Visual Analogue Scale (VAS) with scores ranging from 0 to 10 , according to Downie et al. ${ }^{20}$. When the pain was classified as $\leq 4$, the evaluation was conducted normally, but when the pain was classified as $>4$, analgesia was given, and the pain was classified again after 30 minutes $^{14}$.

\section{Chest X-ray}

A radiological examination of the thorax was performed at the time of hospital discharge, i.e., on the second postoperative day. The highest total lung capacity (TLC) achieved prior to exhalation was required for the X-rays. The analysis of the presence of atelectasis was based on the radiological report of posterior-anterior and lateral chest $\mathrm{x}$-rays in inspiration issued by the hospital's radiologist, who was blinded to the treatments. The radiological reports that showed atelectasis, pulmonary hypoexpansion, or lung area(s) hypoexpansion(s), regardless of size and location, were recorded.

\section{Experimental procedure}

After hospitalization and preoperative evaluation, 43 individuals who fulfilled the inclusion criteria were evaluated and randomly allocated to one of the following groups:

PARG: After the surgical procedure, the individuals in this group were extubated and transferred to the PAR room, where they began treatment through the application of BiPAP by a facial interface for one hour, using the device BiPAP Synchrony II (Philips Respironics, Murrysville, PA, USA). After discharge from the PAR room on the same day of surgery, the individuals were transferred to the hospital room and given conventional chest physical therapy treatment.

1PO-G: The people in this group started the treatment on the first postoperative day (1PO), with two sessions of BiPAP application of 30 minutes each, totaling one hour of treatment on the 1PO.

Both groups received BiPAP with the following settings: positive inspiratory pressure was initially adjusted to $12 \mathrm{cmH} 2 \mathrm{O}$ and subsequently adjusted according to the patient's tolerance while maintaining a respiratory rate between 12 and $20 \mathrm{bpm}$ and a tidal volume between 8 and $10 \mathrm{ml} / \mathrm{kg}$ of ideal weight $\left(\right.$ height $^{2} \mathrm{x}$ ideal BMI). Positive expiratory pressure was set at $8 \mathrm{cmH} 2 \mathrm{O}$.

All individuals in the study received conventional chest physical therapy (CCP) twice a day on immediate postoperative and twice on the 1PO. Sessions included diaphragmatic breathing exercises, deep inspirations, fractional inspirations, breathing exercises combined with upper limb movement and deambulation, prevention of deep vein thrombosis, and the use of incentive spirometry ${ }^{11}$. A set of 15 repetitions was performed for each exercise, with an average duration of 20 to 30 minutes per session.

All people underwent bariatric surgery performed by the same team, under general anesthesia (induction with sevoflurane and propofol and maintenance with remifentanil) and standardized mechanical ventilation with the Dräger Fabius GS ventilator, in volume control mode, with tidal volume of $6-8 \mathrm{~mL} /$ $\mathrm{kg}$, PEEP of $5 \mathrm{cmH} 2 \mathrm{O}$, and fraction of inspired oxygen between 0.4 and 0.6. A pre-operative assessment (on the same day of surgery) and a postoperative assessment (on the second day after surgery) were conducted by the same researcher, who was blind to the treatment groups.

The interventions were always performed by the same researcher, who was blind to the pre-and post-operative assessments.

\section{Data analysis}

For the normally distributed data, we used the Shapiro-Wilk test to compare the spirometric variables, pre and postoperatively (intra-group analysis), the Student's t-test (parametric test) for paired samples, and the Wilcoxon (non-parametric test) for intergroup comparison. For the analysis, BioEstat version 5.3 was used. To compare the prevalence of atelectasis between the groups, the chi-squared (non-parametric test) was used. A significance level of 0.05 was adopted for all analyzes.

\section{RESULTS}

Patients who met the inclusion criteria $(n=43)$ were randomized and allocated to both groups. Before the implementation of interventions, 03 volunteers were excluded (one due to the difficulty in intubation and presence of bronchospasm, generating a bias for respiratory intervention; two others due to surgical complications (fistula) and hospital stay 
FIGURE 1. FLOWCHART OF THE VOLUNTEERS.

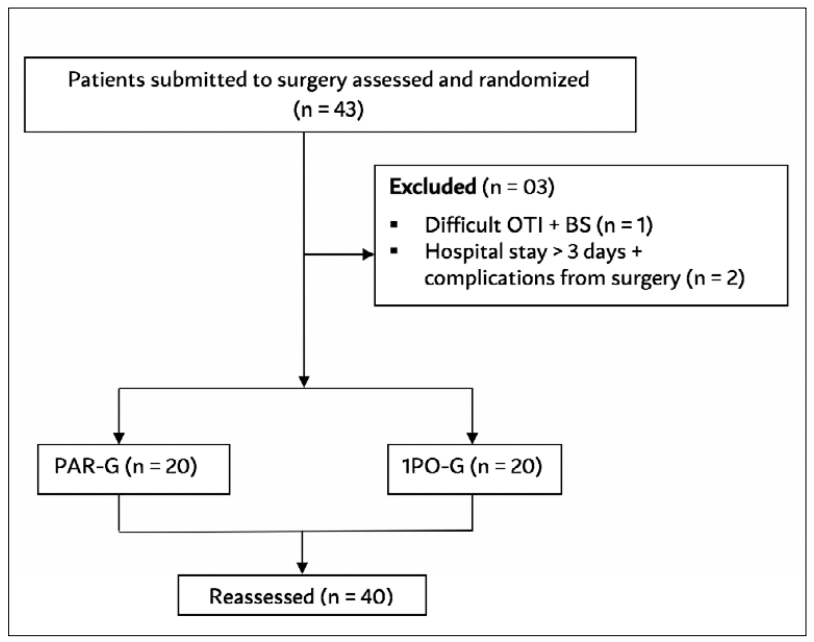

$\mathrm{OTI}$ = orotracheal intubation; $\mathrm{BS}=$ bronchospasm .

greater than 3 days), totaling 40 volunteers divided into 2 groups of 20 each (Figure 1).

Anthropometric and demographic characteristics

In Table 1, the age and anthropometric characteristics of the volunteers are presented for both groups. There was no significant difference between them ( $>0.05)$.

\section{Lung volumes and capacities}

In table 2, the measures for the spirometric variables were shown, obtained in SVC and in FVC for each group as well as the evaluations before and after surgery and statistical results. The results of the statistical analysis of the values of the differences between the preoperative and postoperative periods of the two groups are also shown.

In the PAR-G, there was a significant reduction in SVC ( $p=0.0007), \operatorname{IRV~(~} \mathrm{p}=0.0016)$, and FVC ( $\mathrm{p}=0.0013)$ postoperatively. For ERV ( $p=0.4446)$, there was no difference between the evaluation moments. As for the 1PO-G, there was significant reduction in all variables SVC $(p<0.0001)$, ERV $(p=0.0191)$, VRI $(\mathrm{p}=0.0026)$, and FVC $(\mathrm{p}<0.0001)$. In the intergroup analysis, there were significant differences between the treatments for the variables SVC $(p=0.0027)$ and FVC ( $p=0.0028)$, i.e. the PAR-G showed a smaller decrease in these capacities. As for ERV $(p=0.1646)$ and IRV ( $p=0.3973)$, there was no significant difference between the groups.

\section{Prevalence of atelectasis}

Figure 2 shows the prevalence of atelectasis evaluated by chest X-rays taken on the day of discharge (2PO): $10 \%$ for the PAR-G and 30\% for 1PO-G, with
TABLE 1. GENDER, AGE, AND ANTHROPOMETRIC CHARACTERISTICS OF 40 VOLUNTEERS ALLOCATED TO GROUPS.

\begin{tabular}{l|l|l} 
& \multicolumn{1}{|c|}{ PAR-G } & 1PO-G \\
\hline Gender $(F)$ & 20 & 20 \\
\hline Age (years) & $42.04+6.15$ & $40.14+6.85$ \\
\hline Body mass $(\mathrm{kg})$ & $125.90+10.09$ & $121.48+8.19$ \\
\hline Height $(\mathrm{cm})$ & $158.12+0.10$ & $161.60+1.10$ \\
\hline BMI $\left(\mathrm{kg} / \mathrm{m}^{2}\right)$ & $45.23+7,02$ & $46.12+5.10$ \\
\hline Ideal body mass $(\mathrm{kg})^{\mathbf{a}}$ & $59.68+5,70$ & $62.08+6,90$ \\
\hline
\end{tabular}

$\mathrm{F}=$ female; $\mathrm{BMI}=$ Body mass index; value based on the Metropolitan Life Foundation (1983). Values expressed as mean and standard deviation. No differences between the groups.
gros).

TABLE 2. MEASURES OF SPIROMETRIC VARIABLES, OBTAINED IN THE MANEUVERS FOR SLOW VITAL CAPACITY (SVC) AND FORCED VITAL CAPACITY (FVC) FOR EACH GROUP, PRE- AND POSTOPERATIVELY. STATISTICAL RESULTS OF INTRAGROUP AND INTERGROUP COMPARISONS.

\begin{tabular}{|c|c|c|c|c|c|c|c|c|}
\hline & \multicolumn{3}{|c|}{ PAR-G } & \multirow{2}{*}{\multicolumn{2}{|c|}{ 1PO-G }} & \multirow[b]{3}{*}{ DIF } & \multirow{3}{*}{$\begin{array}{l}\text { p-value } \\
\text { (DIF) }\end{array}$} \\
\hline & & \multicolumn{3}{|c|}{$(n=20)$} & $(n=20)$ & & & \\
\hline & & PRE & POST & DIF & PRE & POST & & \\
\hline SVC & $M$ & 3.34 & 2.78 & 0.56 & 3.63 & 2.47 & 1.16 & $0.0027 \#$ \\
\hline$(\mathrm{L})$ & SD & 0.69 & 0.72 & 0.35 & 0.47 & 0.55 & 0.43 & \\
\hline$p$-va & & 0.00 & & & $<0.0$ & & & \\
\hline ERV & $M$ & 0.5 & 0.49 & 0.01 & 0.72 & 0.52 & 0.20 & 0.1646 \\
\hline$(\mathrm{L})$ & SD & 0.41 & 0.28 & 0.34 & 0.33 & 0.25 & 0.22 & \\
\hline$p$-va & & 0.444 & & & 0.019 & & & \\
\hline IRV & $M$ & 2.17 & 1.57 & 0.6 & 2.18 & 1.37 & 0.81 & 0.3973 \\
\hline$(\mathrm{L})$ & SD & 0.61 & 0.62 & 0.43 & 0.55 & 0.39 & 0.62 & \\
\hline$p$-va & & 0.00 & & & 0.00 & & & \\
\hline FVC & $M$ & 3.54 & 2.95 & 0.59 & 3.61 & 2.49 & 1.12 & $0.0028 \#$ \\
\hline$(\mathrm{L})$ & SD & 0.72 & 0.79 & 0.4 & 0.47 & 0.65 & 0.47 & \\
\hline$p$-va & & 0.00 & & & $<0.0$ & & & \\
\hline
\end{tabular}

PAR-G = post-anesthetic recovery group; $1 P O-G=$ first postoperative day group; $n=$ volunteers al located to each group; $P R E$ = preoperative; $P O S T$ = postoperative; $S V C=$ slow vital capacity; $L=$ liter $E R V:=$ expiratory reserve volume; $I R V=$ inspiratory reserve volume; $F V C=$ forced vital capacity; $M=$ mean; SD = standard deviation; " significant difference between the pre- and postoperative periods; \#: Significant difference between the values of the difference between the pre- and postoperative periods. Values expressed as mean and standard deviation.

FIGURE 2. PREVALENCE OF ATELECTASIS IN GROUPS.

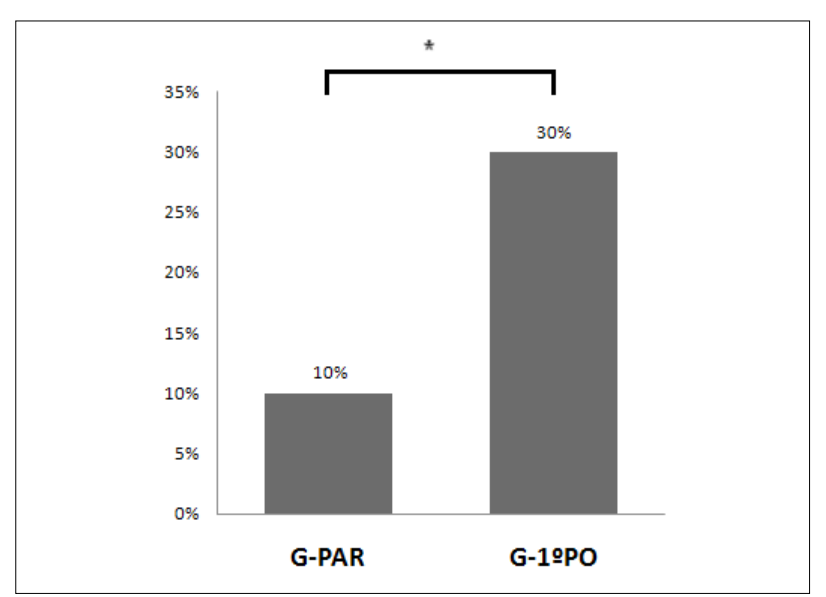

* Significant difference between groups: $p=0.0027$ 
a significant difference between the proportions $(\mathrm{p}=0.0027)$.

\section{DISCUSSION}

In summary, in the PAR-G and 1PO-G, respectively there were significant reductions in SVC, IRV, and FVC but ERV was maintained only for the PAR-G. Comparing the groups, the SVC and FVC showed a significant difference between the treatments; the PAR-G showed smaller declines in these capacities. The prevalence of atelectasis was 10\% for the PAR-G and $30 \%$ for the 1 PO-G.

In this study, there was a decrease in the spirometric variables SVC, FVC, and IRV compared to preoperative values in both groups. In fact, after any surgical procedure, particularly those to the upper abdomen, a decrease in lung volume and capacity is expected, as well as increased respiratory muscle dysfunction ${ }^{21}$ and impaired gas exchange.

Such postoperative conditions are generated due to compression of the lung parenchyma by cephalic diaphragm displacement, especially in the supine position, but also to the early collapse of the airways of the lung-dependent regions ${ }^{17}$ and manipulation of the abdominal cavity. These factors reduce the $\mathrm{FRC}^{22}$ and worsen the pain, the limitation in deep inspiration ${ }^{23}$, and the precondition of alveolar hypoventilation. The increase in fat in the abdominal area and the changes in ventilatory mechanics ${ }^{24}$ predispose the obese individual to respiratory complications when combined with general anesthesia, especially in the early hours during their stay in the recovery room $^{25}$.

According to Chau et al. ${ }^{26}$, morbidly obese individuals present alveolar hypoventilation, which, combined with anesthetic procedures, influence the decrease in postoperative lung volumes and capacities. These findings are more detectable immediately after extubation.

However, there was a smaller decrease in SVC and FVC in the group that received positive pressure while still in the PAR, as well as, maintenance of ERV. Therefore, the use of BiPAP immediately after extubation, in the PAR, may have corrected the alveolar hypoventilation and expanded areas that collapsed during the surgical procedure. These results are evident in this study and reflect a lower prevalence of postoperative atelectasis in the PAR-G compared to the 1PO-G.

Eichenberger et al. ${ }^{27}$ studied morbidly obese and eutrophic individuals evaluated using computed tomography of the thorax and analyzed the presence of atelectasis in three moments: before anesthetic induction for high abdominal surgery, immediately after extubation, and 24 hours after extubation. The authors observed that, among obese individuals, the rate of atelectasis was high even before the anesthesia. After extubation, both groups presented greater alveolar collapse. However, 24 hours later, eutrophic individuals presented a fall in atelectasis, while the obese ones showed an increased prevalence of atelectasis.

According to Melero et al. ${ }^{28}$, the deterioration of lung function seems to be more evident within the first 24 hours, which can justify the use of positive pressure in this most critical period, as performed in the present study.

The chest X-ray of the present study was performed on the $2^{\text {nd }} \mathrm{PO}$, in other words, 48 hours after the surgical procedure, demonstrating that the lung hypoexpansion of these people remains during this period and that, although subclinical, it may trigger other pulmonary complications and thus effective prophylactic measures should be studied.

Non-invasive positive pressure ventilation (NPPV) has been used successfully in postoperative patients after abdominal surgery ${ }^{13,29}$ to reverse atelectasis, restore FRC, and prevent the collapse of the upper airways and lung complications ${ }^{30}$.

The use of BiPAP, in particular, seems to be more effective when applied within the first 48 hours after extubation in morbidly obese people ${ }^{31}$. Prophylactic application of positive pressure after gastroplasty has shown improvement of gas exchange and lung function when compared to the use of oxygen therapy alone ${ }^{32}$. The results of Pessoa et al. ${ }^{31}$ corroborate these studies by showing a comparison of the use of BiPAP with oxygen therapy in the recovery room. Although the authors did not demonstrate a significant difference in the prevalence of atelectasis, they found that the group that carried out NPPV evolved with better oxygenation, probably by increasing the FRC promoted by positive pressure without compromising the integrity of the gastrojejunal anastomosis.

In this study, the fact that the ERV did not change compared to preoperative values in the PAR-G shortly after extubation and that the 1PO-G had lower values demonstrates the need to reexpand collapsed alveolar units as early as possible. A study by Baltieri et al. ${ }^{16}$ comparing the use of positive pressure in the 
preoperative, intraoperative, and immediate postoperative phases demonstrated that it is always beneficial in restoring the ERV; however, when applied in the immediate postoperative, it decreases the prevalence of atelectasis.

Therefore, the use of BiPAP in the PAR demonstrates the best results in the restoration of lung volumes and capacity and the decrease in the prevalence of atelectasis. However, in most Brazilian institutions, the role of the physiotherapist in the ARRs is not part of the routine, and there are challenges in its insertion in the multi-professional team. Nevertheless, studies such as this reinforce the benefits of having the professional present in PAR to identify patients at risk for physical therapy treatment and thus contribute to better and faster healing of surgical patients.

\section{STUDY LIMITATIONS}

The small number of individuals evaluated and the lack of a control group. Most bariatric procedures are laparoscopically performed over recent years; this approach might have led to different results if the same interventions were performed.

\section{CONCLUSION}

The application of bilevel positive pressure in people with morbid obesity during post-anesthet- ic recovery, i.e., immediately after extubation, following bariatric surgery can bring more benefits in relation to the maintenance of volumes and lung capacity and decrease in the appearance of atelectasis than when applied on the first day after surgery. The application of BiPAP in the anesthetic recovery room can also be beneficial in the maintenance of the ERV, which is considered the most affected volume in morbid obesity.

Based on the results of this study, it can be concluded that, although there are difficulties in inserting the physical therapist in ARRs, this seems to be the most effective moment for the implementation of chest physical therapy, especially the application of bilevel positive pressure.

\section{Institution}

Universidade Metodista de Piracicaba (Unimep)

Faculdade de Ciências da Saúde, Programa de Pós-Graduação em Ciências do Movimento Humano, Universidade Metodista de Piracicaba, Unimep, Piracicaba, SP-Brasil

Rodovia do Açúcar, km 156 - Piracicaba - São Paulo (SP) - Brasil, CEP 13400-911. Tel.: (+55 11) 31241558; Fax: (+55 19) 3124-1500

\section{Funding}

São Paulo Research Foundation (Fapesp), process number 2013/w-8 Research Ethics Committee: protocol approval 89/12

\section{RESUMO}

OBJETIVO: Investigar o uso da pressão positiva em dois níveis nas vias aéreas (BiPAP) em obesos mórbidos em dois momentos após a cirurgia bariátrica (bypass gástrico em Y-de-Roux): recuperação pós-anestésica (RPA) e primeiro dia de pós-operatório (1PO).

DESENHO: Ensaio clínico randomizado e cego.

MÉTODO: Foram estudados 40 obesos mórbidos, com idade entre 25 e 55 anos, submetidos à prova de função pulmonar e radiografia de tórax no pré-operatório e no dia da alta (segundo dia de pós-operatório). Eles foram alocados aleatoriamente em dois grupos: G-RPA (BiPAP na RPA por uma hora) e G-1PO (BiPAP por uma hora no 1PO).

RESULTADOS: No G-RPA e G-1PO, respectivamente, houve reduções significativas na capacidade vital lenta (CVL) ( $p=0,0007$ vs p<0,0001), volume de reserva inspiratório (VRI) ( $p=0,0016$ vs $p=0,0026)$ e capacidade vital forçada (CVF) ( $p=0,0013$ vs $p<0,0001)$. O volume de reserva expiratório (VRE) foi mantido apenas para o G-RPA ( $p=0,4446$ vs $p=0,0191$ ). Comparando os grupos, a CVL ( $p=0,0027)$ e a CVF ( $p=0,0028$ ) apresentaram diferenças significativas entre os tratamentos e o G-RPA apresentou menores declínios nessas capacidades. A prevalência de atelectasia foi de $10 \%$ para o G-RPA e 30\% para o $1 P O-G(p=0,0027)$.

CONCLUSÃO: O uso de BiPAP na RPA pode promover uma restauração do VRE e contribuir para a redução de atelectasias.

PALAVRAS-CHAVE: Atelectasia pulmonar. Cirurgia bariátrica. Modalidades de fisioterapia. Testes de função respiratória. Pressão positiva contínua nas vias aéreas. 


\section{REFERENCES}

1. Brasil. Ministério da Saúde. Vigitel Brasil 2017. Vigilância de fatores de risco e proteção para doenças crônicas por inquérito telefônico. Brasília: Ministério da Saúde; 2018. [Accessed in 2019 Jan 19]. Available from: http://bvsms. saude.gov.br/bvs/publicacoes/vigitel_brasil_2017_vigilancia_fatores_riscos. pdf.

2. World Health Organization. Obesity and overweight [homepage on internet]. [Updated in 16 Feb 2018; acessed on 28 Jan 2019]. Available from: https:// www.who.int/en/news-room/fact-sheets/detail/obesity-and-overweight

3. Sjöström L. Bariatric surgery and reduction in morbidity and mortality: experiences from the SOS study. Int J Obes (Lond). 2008;32(Suppl 7):S93-7.

4. Pentin PL, Nashelsky J. What are the indications for bariatric surgery? J Fam Pract. 2005;54(7):633-4.

5. Chung F, Mezei G, Tong D. Pre-existing medical conditions as predictors of adverse events in day-case surgery. Br J Anaesth. 1999;83(2):262-70.

6. Livingston EH, Huerta S, Arthur D, Lee S, De Shields S, Heber D. Male gender is a predictor of morbidity and age a predictor of mortality for patients undergoing gastric bypass surgery. Ann Surg. 2002;236(5):576-82.

7. Nguyen NT, Lee SL, Goldman C, Fleming N, Arango A, McFall R, et al. Comparison of pulmonary function and postoperative pain after laparoscopic versus open gastric bypass: a randomized trial. J Am Coll Surg. 2001;192(4):469-76.

8. DeMaria EJ, Portenier D, Wolfe L. Obesity surgery mortality risk score: proposal for a clinically useful score to predict mortality risk in patients undergoing gastric bypass. Surg Obes Relat Dis. 2007;3(2):134-40.

9. Smetana GW, Lawrence VA, Cornell JE; American College of Physicians. Preoperative pulmonary risk stratification for noncardiothoracic surgery: systematic review for the American College of Physicians. Ann Intern Med. 2006;144(8):581-95.

10. Chawla G, Drummond GB. Fentanyl decreases end-expiratory lung volume in patients anaesthetized with sevoflurane. Br J Anaesth. 2008;100(3):411-4.

11. Forti E, Ike D, Barbalho-Moulim M, Rasera I Jr, Costa D. Effects of chest physiotherapy on the respiratory function of postoperative gastroplasty patients. Clinics. 2009;64(7):683-9.

12. Brigatto P, Carbinatto JC, Costa CM, Montebelo MI, Rasera-Júnior I, Pazzianotto-Forti EM. Application of positive airway pressure in restoring pulmonary function and thoracic mobility in the postoperative period of bariatric surgery: a randomized clinical trial. Braz J Phys Ther. 2014;18(6):553-62.

13. Jaber S, Delay JM, Chanques G, Sebbane M, Jacquet E, Souche B, et al. Outcomes of patients with acute respiratory failure after abdominal surgery treated with noninvasive positive pressure ventilation. Chest. 2005;128(4):2688-95.

14. Gaszynski T, Tokarz A, Piotrowski D, Machala W. Boussignac CPAP in the postoperative period in morbidly obese patients. Obes Surg. 2007;17(4):452-6.

15. Remístico PP, Araújo S, Figueiredo LC, Aquim EE, Gomes LM, Sombrio ML et al. Impact of alveolar recruitment maneuver in the postoperative period of videolaparoscopic bariatric surgery. Rev Bras Anestesiol. 2011;61(2):163-8.
16. Baltieri L, Santos LA, Rasera I Jr, Montebelo MI, Pazzianotto-Forti EM. Use of positive pressure in the bariatric surgery and effects on pulmonary function and prevalence of atelectasis: randomized and blinded clinical trial. Arq Bras Cir Dig. 2014;27(Suppl 1):26-30.

17. Sood A. Altered resting and exercise respiratory physiology in obesity. Clin Chest Med. 2009;30(3):445-54.

18. ATS/ERS Task Force. Standardisation of lung function testing: standardisation of spirometry. Eur Respir J. 2005;26(2):319-38.

19. Pereira CAC. Directives for pulmonary function tests. I Pneumol. 2002;28(3):1-82

20. Downie WW, Leatham PA, Rhind VM, Wright V, Branco JA, Anderson JA. Studies with pain rating scales. Anna Rheum Dis. 1978;37(4):378-81.

21. Barbalho-Moulim MC, Miguel GPS, Forti EM, Campos FA, Costa D. Effects of preoperative inspiratory muscle training in obese women undergoing open bariatric surgery: respiratory muscle strength, lung volumes, and diaphragmatic excursion. Clinics. 2011;66(10):1721-7.

22. Levi D, Goodman ER, Patel M, Savransky Y. Critical care of the obese and bariatric surgical patient. Crit Care Clin. 2003;19(1):11-32.

23. Smith MCL, Ellis ER. Is retained mucus a risk factor for the development of postoperative atelectasis and pneumonia? Implications for the physiotherapist. Physiother Theory Pract. 2000;16(2):69-80.

24. Zammit C, Liddicoat H, Moonsie I, Makker H. Obesity and respiratory diseases. Int J Gen Med. 2010;3:335-43.

25. Moore CE, Forrest M, Ammori B. Anaesthesia for obesity surgery. Anaesth Intensive Care Med. 2011;12(7):280-2

26. Chau EH, Lam D, Wong J, Mokhlesi B, Chung F. Obesity hypoventilation syndrome: a review of epidemiology, pathophysiology, and perioperative considerations. Anesthesiology. 2012;117(1):188-205.

27. Eichenberger AS, Proietti S, Wicky S, Frascarolo P, Suter M, Spahn DR, et al. Morbid obesity and postoperative pulmonary atelectasis: an underestimated problem. Anesth Analg. 2002;95(6):1788-92.

28. Melero A, Vallés J, Vila P, Canet J, Vidal F. Anesthesia recovery, gas exchange and postoperative hepatic and renal function in patients with morbid obesity undergoing bariatric surgery: comparison of the effects of halothane, isoflurane and fentanyl. Rev Esp Anestesiol Reanim. 1993;40(5):268-72.

29. Conti G, Cavaliere F, Costa R, Craba A, Catarci S, Festa V, et al. Noninvasive positive-pressure ventilation with different interfaces in patients with respiratory failure after abdominal surgery: a matched-control study. Respir Care. 2007;52(11):1463-71.

30. Sungur M, Layon AJ, Gabrielli A. Treatment of postoperative respiratory insufficiency in the obese patient: who makes the call? Obes Surg. 2007;17(4):457-9.

31. Pessoa KC, Araújo GF, Pinheiro AN, Ramos MRS, Maia SC. Ventilação não invasiva no pós-operatório imediato de derivação gastrojejunal com bypass em Y de Roux. Rev Bras Fisioter. 2010;14(4):290-6.

32. Liesching $T$, Kwok $H$, Hill NS. Acute applications of noninvasive positive pressure ventilation. Chest. 2003;124(2):699-713. 